\title{
Nova espécie de Hesperandra Arigony da Bolívia (Coleoptera, Cerambycidae, Parandrinae)
}

\section{Antonio Santos-Silva ${ }^{1}$}

\begin{abstract}
New species of Hesperandra Arigony from Bolivia (Coleoptera, Cerambycidae, Parandrinae). Hesperandra thomasi sp. nov. is described and illustrated.

KEY WORDS. Coleoptera, Cerambycidae, Parandrinae, Hesperandra, South America, taxonomy
\end{abstract}

Entre os Parandrinae, o gênero Hesperandra Arigony, 1977, é o que apresenta maior dificuldade para a identificação de suas espécies (exclusivamente americanas), em geral muito variáveis em forma e tamanho. São freqüentes os espécimes que só com muita experiência no grupo podem ser corretamente identificados. O estudo de material recebido para identificação, proveniente da Bolívia, revelou a existência de uma nova espécie.

As siglas citadas no texto correspondem as seguintes instituições: FSCA, Florida State Collection of Arthropods, Gainesville, EUA; MNKM, Museo de Historia Natural "Noel Kempff Mercado", Santa Cruz de la Sierra, Bolívia; MZSP, Museu de Zoologia da Universidade de São Paulo, São Paulo.

\section{Hesperandra thomasi sp. nov.}

Figs 1-12

Etimologia. A espécie é dedicada ao Dr. Michael C. Thomas (FSCA) pelas diversas gentilezas.

Macho (Fig. 1). Tegumento castanho-brilhante, mais escuro na cabeça. Cabeça grande e subquadrada. Vértice com pontos finos e esparsos. Fronte com pontos finíssimos e mais cerrados do que no vértice. Área posterior dos olhos com pontos moderadamente grossos, profundos e, em parte, confluentes. Suturas epistomal e clípeo-labral indicadas. Ápice do labro (Fig. 7) saliente (não ou apenas ultrapassa os cantos látero-anteriores da cabeça). Carenas oculares salientes e precedidas por sulco bem-marcado. Lobos inferiores (Fig. 4) pouco alargados. Genas com pontos pequenos e esparsos; depressão lateral profunda e bem-marcada; ápices salientes. Submento com pontos pequenos, rasos e esparsos, nos quais se implanta um pêlo microscópico; sulco da margem anterior raso. Mento e lígula com pilosidade abundante, moderadamente longa. Mandíbulas (Fig. 7) falciformes; carena dorsal elevada no terço basal, com a aresta interna perpendicular ao eixo longitudinal; depressão dorsal das mandíbulas bem-delimitada; margem interna opaca, curva da base ao dente, este triangular e pequeno, pouco depois do meio; ápice bífido e largo. Palpos maxilares alongados.

1) Museu de Zoologia, Universidade de São Paulo. Caixa Postal 42594, 04299-970 São Paulo, São Paulo, Brasil. 


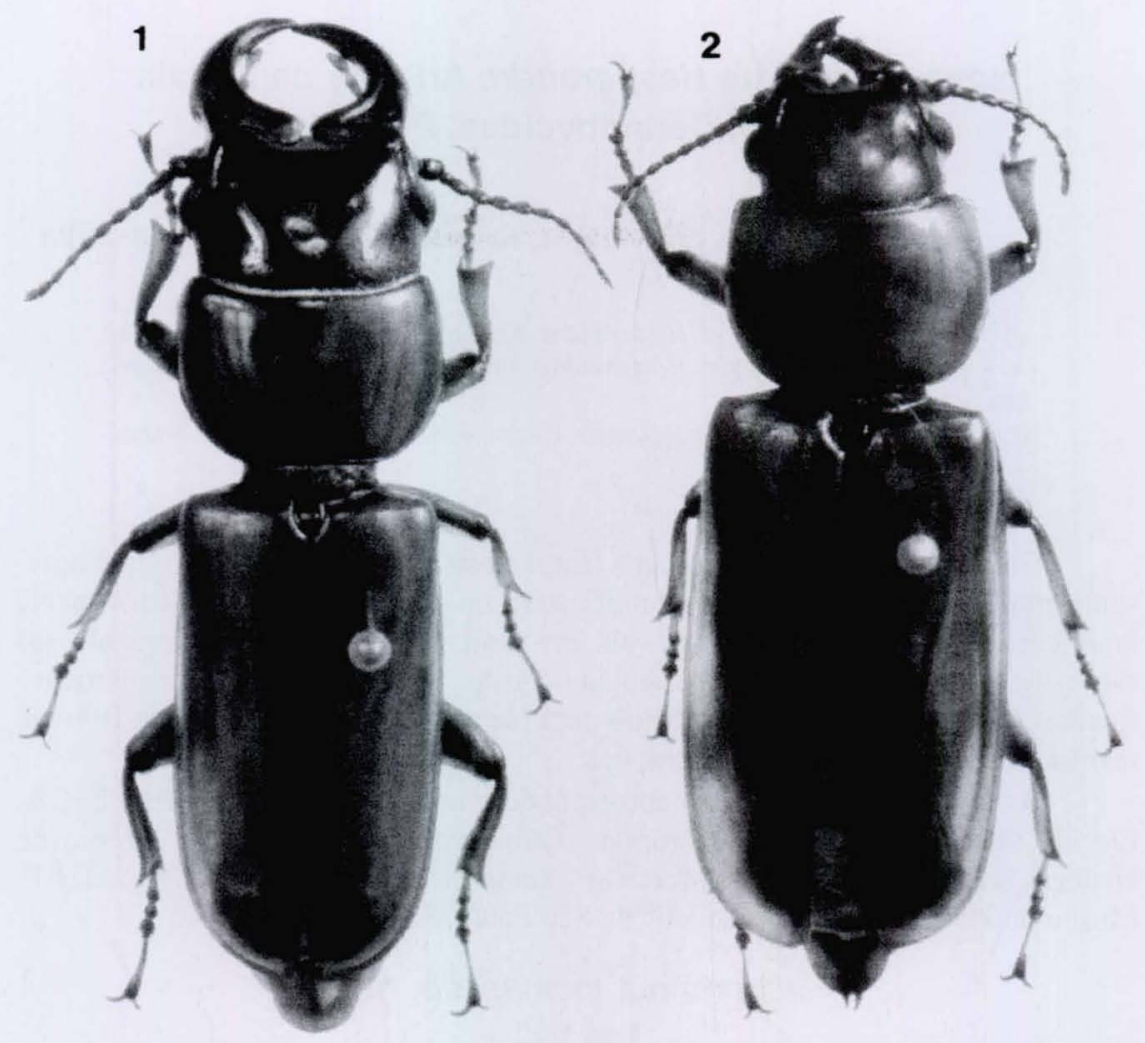

Figs 1-2. Hesperandra thomasi sp. nov.: (1) holótipo macho, comprimento $35,3 \mathrm{~mm}$; (2) parátipo fêmea, comprimento $34,0 \mathrm{~mm}$.

Gálea pouco pilosa; ápice atinge a metade do segundo artículo dos palpos maxilares. Antenômeros (Fig. 5) curtos e largos; carena das áreas sensoriais pouco visível em vista lateral (exceto nos antenômeros IX-XI).

Protórax transversal. Pronoto microscopicamente pontuado; margens enegrecidas; margem anterior côncava; marginação lateral completa; ângulos anteriores suavemente salientes e arredondados; ângulos posteriores arredondados. Processo prosternal pouco saliente; ápice arredondado. Mesepisternos com pontos pequenos e esparsos, mais concentrados em direção às procoxas. Mesepimeros com alguns pontos próximos aos metepisternos. Metasterno liso e glabro. Metepisternos com raros pontos e pêlos curtos próximo aos mesepimeros. Élitros com pontos finíssimos.

Quatro primeiros urosternitos quase glabros e não-pontuados no centro; lados com pontos e pêlos moderadamente abundantes. Último urosternito pontuado nos lados e com asperezas diminutas no centro; bordas com franja rala de pêlos; ápice uniformemente arredondado ou suavemente truncado. Fêmures glabros e lisos. Tíbias com pêlos curtos na face inferior; esporão externo longo (atinge o ápice do primeiro tarsômero). 

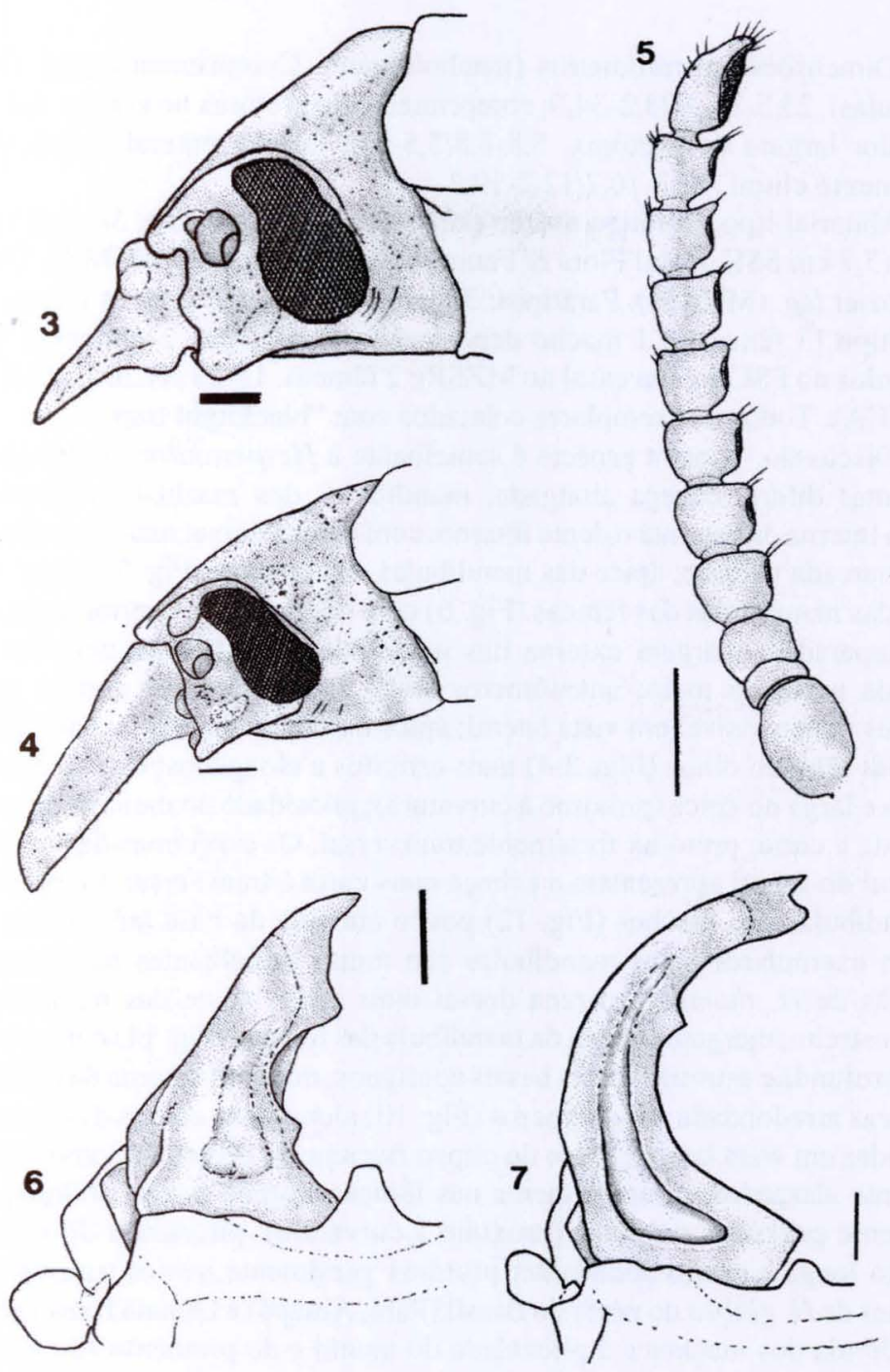

Figs 3-7. Hesperandra thomasi sp. nov. - (3-4) cabeça, vista lateral: (3) parátipo fêmea; (4) holótipo macho; (5) antena, vista lateral, parátipo macho; (6-7) mandíbula esquerda: (6) parátipo fêmea; (7) holótipo macho. Barra $=1 \mathrm{~mm}$.

Fêmea (Fig. 2). Cabeça menor do que no macho. Ápice do labro (Fig. 6) ultrapassa os cantos látero-anteriores da cabeça. Mandíbulas (Fig. 6) curtas e não-falciformes; margem externa fortemente estreitada após o terço basal; margens internas côncavas no meio; dentes basais da margem interna separados. Ápice das genas pouco projetado. Protórax mais alongado. Élitros proporcionalmente maiores do que nos machos. 
Dimensões em milímetros (macho/fêmea). Comprimento total (inclusive mandíbulas), 23,5-35,3/23,2-34,0; comprimento do protórax no centro, 4,0-5,5/4,16,0; maior largura do protórax, 5,8-8,8/5,5-9,0; largura umeral, 6,0-8,3/5,9-9,0; comprimento elitral, 12,3-16,7/12,2-19,2.

Material-tipo. Holótipo macho proveniente da BOLÍVIA, Santa Cruz: Buenavista (3,7 km SSE, Hotel Flora \& Fauna, $430 \mathrm{~m}$ ), 5-15.XI.2001, M.C. Thomas \& B.K. Dozier leg. (MNKM). Parátipos: 3 machos e 6 fêmeas com os mesmos dados do holótipo (3 fêmeas e 1 macho depositados no MNKM, 2 fêmeas e 1 macho depositados no FSCA e um casal no MZSP); 2 fêmeas, 15-22.XI.2001, B.K. Dozier leg. (FSCA). Todos os exemplares coletados com "blacklight trap".

Discussão. A nova espécie é semelhante à Hesperandra glabra (De Geer, 1774), mas difere: cabeça alongada; mandíbulas dos machos arredondadas na margem interna da base até o dente interno, com carena dorsal mais elevada, estreita e bem marcada na base; ápice das mandíbulas dos machos (Fig. 7) largo; margem interna das mandíbulas das fêmeas (Fig. 6) com concavidade central larga e dentes basais separados; margem externa das mandíbulas das fêmeas com reentrância acentuada perto do meio; antenômeros (Fig. 5) mais curtos; carena das áreas sensoriais pouco visível em vista lateral; ápice do clípeo mais projetado, principalmente nas fêmeas; olhos (Figs 3-4) mais estreitos e alongados; carena ocular mais alta, reta e larga no ápice (próximo à curvatura); pilosidade do mento e do premento abundante e curta; protórax fortemente transversal. Os espécimes de $\mathrm{H}$. glabra do centro-sul do Brasil apresentam a cabeça mais curta e transversal; margem interna das mandíbulas dos machos (Fig. 12) pouco curvada da base até o dente interno (existem exemplares cujas mandíbulas são muito semelhantes na metade basal interna às de $H$. thomasi); carena dorsal mais larga; ápice das mandíbulas dos machos estreito; margem interna da mandíbula das fêmeas (Fig. 11) com reentrância central profunda e estreita; dentes basais contíguos; margem externa das mandíbulas das fêmeas arredondada; antenômeros (Fig. 10) alongados; carena das áreas sensoriais nítidas em vista lateral; ápice do clípeo fracamente projetado; olhos (Figs 8-9) fortemente alargados, principalmente nas fêmeas; carena ocular oblíqua, baixa e nitidamente estreitada no ápice (próximo à curvatura); pilosidade do mento e do premento longa e muito abundante; protórax geralmente menos transversal. Nos espécimes de $H$. glabra do norte do Brasil (Pará, Amapá) e Guiana Francesa o ápice da mandíbula dos machos e a pilosidade do mento e do premento são geralmente semelhantes aos de $H$. thomasi.

Hesperandra glabra é espécie com larga distribuição geográfica e apresenta muitas formas regionais que provavelmente constituem subespécies. No entanto, todas compartilham o mesmo tipo de mandíbula nas fêmeas e o mesmo formato de cabeça nos machos (exceto alguns exemplares aberrantes).

THOMSON (1861a, b) descreveu duas espécies que atualmente estão na sinonímia de H. glabra: Parandra grandis e P. barbata provenientes da Colômbia. Esses espécimes (machos) apresentam mandíbulas estreitas na base como em $H$. thomasi, mas diferem pela cabeça mais transversal, ápice das mandíbulas e protórax. 

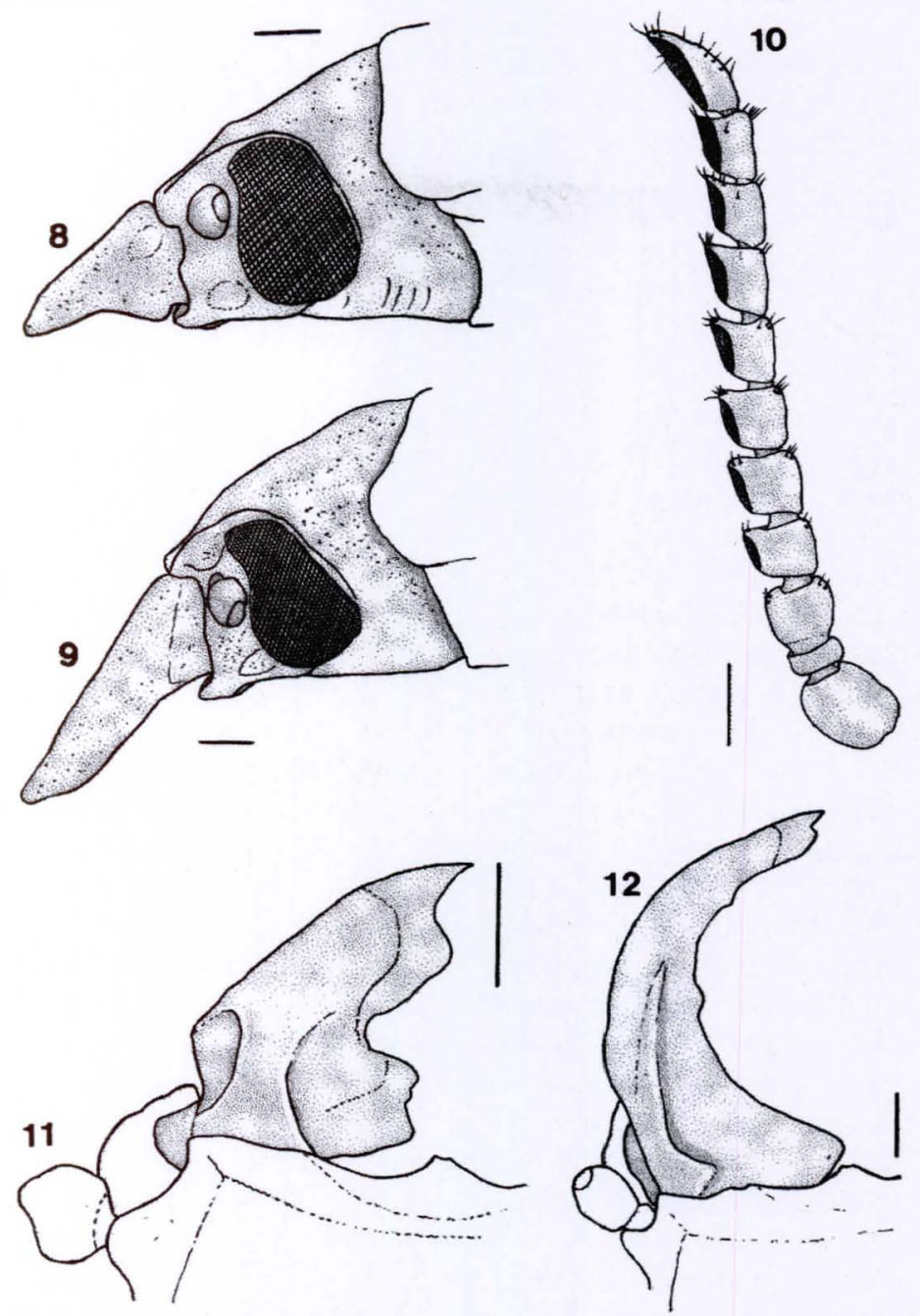

Figs 8-12. Hesperandra glabra - (8, 9) cabeça, vista lateral: (8) fêmea; (9) macho; (10) antena, vista lateral macho; (11-12) mandíbula esquerda: (11) fêmea; (12) macho. Os espécimes figurados são provenientes da região Sudeste do Brasil. Barra $=1 \mathrm{~mm}$.

AGRADECIMENTOS. Ao Dr. Michael C. Thomas do FSCA, pelo empréstimo do material para estudo e ao Dr. Ubirajara R. Martins pelo constante incentivo.

\section{REFERÊNCIAS BIBLIOGRÁFICAS}

Thomson, J. 1861a. Monographie de la Famille des Parandrides. Mus. scient., Paris, 2: 73-87. 1861b. Note rectificative et corrections. Mus. scient., Paris, 2: 95-96.

Recebido em 30.V.2002; aceito em 10.IX.2002. 